University of Montana

ScholarWorks at University of Montana

2014

\title{
Environmental melodrama, coal, and the politics of sustainable energy in The Last Mountain
}

\author{
Steven J. Schwarze \\ University of Montana - Missoula, steven.schwarze@umontana.edu \\ Jennifer Peeples \\ Utah State University \\ Jen Schneider \\ Colorado School of Mines \\ Pete Bsumek \\ James Madison University
}

Follow this and additional works at: https://scholarworks.umt.edu/communications_pubs Let us know how access to this document benefits you.

\section{Recommended Citation}

Schwarze, Steven J.; Peeples, Jennifer; Schneider, Jen; and Bsumek, Pete, "Environmental melodrama, coal, and the politics of sustainable energy in The Last Mountain" (2014). Communication Studies Faculty Publications. 15.

https://scholarworks.umt.edu/communications_pubs/15

This Article is brought to you for free and open access by the Communication Studies at ScholarWorks at University of Montana. It has been accepted for inclusion in Communication Studies Faculty Publications by an authorized administrator of ScholarWorks at University of Montana. For more information, please contact

scholarworks@mso.umt.edu. 


\title{
Environmental melodrama, coal, and the politics of sustainable energy in The Last Mountain
}

\section{Steve Schwarze*}

Department of Communication Studies,

The University of Montana,

Missoula, MT 59812, USA

E-mail: Steven.schwarze@umontana.edu

*Corresponding author

\section{Jennifer Peeples}

Department of Languages, Philosophy and

Communication Studies,

Utah State University,

0720 Old Main Hill,

Logan, Utah 84322-0720, USA

E-mail: jennifer.peeples@usu.edu

\section{Jen Schneider}

Liberal Arts and International Studies,

Colorado School of Mines,

1005 14th St., Golden, CO 80401, USA

E-mail: Jen.schneider@mines.edu

\section{Pete Bsumek}

School of Communication Studies, James Madison University, MSC 2106, 54 Bluestone Dr., Harrisonburg, VA 22807, USA

E-mail: bsumekpk@jmu.edu

\begin{abstract}
The Last Mountain is a 2011 Natural Resources Defense Council (NRDC) film. It examines an aggressive form of strip mining in West Virginia known as mountaintop removal (MTR). The Last Mountain was the first of more than 40 MTR films to be distributed nationally and, as such, marks the entry of the issue onto the political scene in the USA. This essay analyses the film's use of environmental melodrama to define the problems related to MTR and create identification between victims of MTR and viewers. However, the latter portion of the film attempts to scale up from the melodramatic depiction of MTR to advocacy on broader issues regarding renewable energy and global climate change. In doing so, the film breaks with melodramatic form, draining its emotional power, foreclosing systemic political action, and limiting its overall effectiveness as a sustainability narrative.
\end{abstract}


Keywords: mountaintop removal; MTR; environmental melodrama; environmental documentary; The Last Mountain; TLM; coal; sustainable energy; sustainable development.

Reference to this paper should be made as follows: Schwarze, S., Peeples, J., Schneider, J. and Bsumek, P. (2014) 'Environmental melodrama, coal, and the politics of sustainable energy in The Last Mountain', Int. J. Sustainable Development, Vol. 17, No. 2, pp.108-122.

Biographical notes: Steve Schwarze is an Associate Professor and Chair in the Department of Communication Studies at The University of Montana, USA.

Jennifer Peeples is an Associate Professor in the Department of Languages, Philosophy and Communication Studies at Utah State University, USA.

Jen Schneider is an Associate Professor of Liberal Arts and International Studies at the Colorado School of Mines, USA.

Pete Bsumek is an Associate Professor of Communication Studies and Co-Director of Center for Health and Environmental Communication at James Madison University, USA.

This paper is a revised and expanded version of a paper entitled 'Not the last mountain: mountaintop removal documentaries and coalition building' presented at the Western States Communication Association Conference, Albuquerque, NM, February 2012.

"Coal is mean. Coal is cruel. And coal kills. And the American people need to find their position, where that is. You're connected to coal whether you realize it or not. Everybody's connected to this and everybody's causing it and everybody's allowing it."

-- Maria Gunnoe, The Last Mountain

\section{Introduction}

In 2011, the US environmental organisation Natural Resources Defense Council (NRDC) produced The Last Mountain (TLM), a feature-length documentary film that examined mountaintop removal (MTR) in the Appalachian region of the USA. MTR is a particularly aggressive form of strip mining whereby the tops of mountains are exploded, revealing rich coal seams beneath the surface. However, such mining also poses significant environmental and public health threats and perpetuates the burning of fossil fuel that contributes to global climate change. Although TLM certainly is not the first documentary made about MTR in Appalachia, it was the first to be nationally distributed. The NRDC's role as a major national environmental group heightened the prominence of the film: it was screened at the influential Sundance Film Festival, and it received a noteworthy amount of press coverage (Press, 2012).

Both the film's prominence and its modes of framing make it an excellent case for considering the challenges and opportunities in crafting sustainability narratives. In this essay, we offer a rhetorical analysis of $T L M$ as an instance of 'environmental 
melodrama', a frame for narrating environmental controversy that encourages strong viewer affiliation with victims of environmental degradation and injustice, and antipathy toward the perpetrators of the degradation and injustice. We argue that the narrative of $T L M$ struggles in its attempt to 'scale up' from its compelling melodramatic depiction of local MTR conflicts in Appalachia to advocacy regarding renewable energy sources and global climate change. Our analysis identifies three aspects of the film that hinder its capacity to scale up the local melodramatic story into a broader sustainability narrative: the inability to sustain viewer identification, the lack of connection between individual responsibility and collective action, and the narrow focus on technological solutions to the problems of MTR.

This analysis contributes to the emerging scholarly literature at the intersection of environmental communication and film (e.g., Rosteck and Frentz, 2009; Schutten, 2008; Wolfe, 2009; DeLaure, 2011; Schneider and Miller, 2011). We note with interest Adrian Ivakhiv's (2008, p.13) recommendation that environmental communication might benefit from more sustained interaction with film studies that open "up the question of cinema's visceral effects, that is, those which may elude consciousness but which carry an emotional and affective charge capable of engendering deep responses". Following Ivakhiv's recommendation, we examine how the film uses melodramatic narrative framing to create visceral cinematic effects and position audiences for collective action. Taking a constitutive perspective on communication (Cox, 2010), we do not attempt to describe how the film affects specific audiences (an empirical question of media effects). Instead, we consider how various features of environmental melodrama position an audience that is "rhetorically constituted as a collective ethical subject through an articulation of experience" [Charland, (1990), p.466]. Environmental melodrama helps explain an affective valence in filmmaking that has the potential to promote identification between viewers and the subjects of the film, raise ecological consciousness, and enhance political agency.

Consequently, this analysis also contributes to scholarly and practical understanding of environmental melodrama as a rhetorical form. Critics such as Terence Check (Kinsella et al., 2008) and DeLaure (2011) have argued that environmental melodrama is ill-suited for addressing diffuse, systemic issues such as energy consumption and global climate change. Although we observe that the environmental melodrama of TLM ultimately fails to overcome the concerns of these critics, we also highlight missed opportunities where the film might have created more effective engagement with the systemic aspects of energy and climate issues. Following the analysis, our implications explain how TLM could have been a stronger sustainability narrative if it had, in fact, maintained greater fidelity to the melodramatic form. These implications suggest ways that environmental melodrama can be successfully adapted to address systemic environmental problems.

\section{Environmental melodrama}

TLM relies heavily on the frame of 'environmental melodrama' (Kinsella et al., 2008; Schwarze, 2006) to develop a narrative about MTR in Appalachia. As defined by Schwarze (2006, p.168), melodrama is "a rhetorical frame that employs highly moral and emotional appeals to stage social conflict between polarized actors". These inter-related features of melodrama help narrators craft a compelling and recognisable narrative $-\mathrm{a}$ 
story with clearly defined victims, villains, and heroes that generates audience identification with specific actors. In this section, we briefly explain the basic features and rhetorical action of melodrama before analysing TLM as an instance of melodrama.

The melodramatic frame is characterised by four interrelated features: "a focus on socio-political conflict, polarization of characters and positions, a moral framing of public issues, and development of monopathy" [Schwarze, (2006), p.245]. The first feature, a focus on socio-political conflict, distinguishes narratives that identify a clear tension between opposing interests from narratives that dwell on the personal journey of an individual or that avoid discussions of political conflict. In the context of sustainability, the melodramatic frame translates personal dilemmas or private troubles into public problems and displays the power dynamics at work in a particular situation. For example, the melodramatic frame would not focus on how one family was affected by an environmental crisis, as an evening television news story might. Rather, it would frame the family's situation as evidence of a larger power play involving competing interests, by showing how others benefit economically from causing the crisis in the first place.

Second, melodrama tends to polarise the characters and positions in conflict. Where other frames might encourage compromise or identify a middle ground between competing actors, melodrama heightens conflict and questions the possibility of reconciling competing interests. Polarisation can reveal tensions between these interests that have been submerged or distorted by specious notions of the public interest. Although this kind of polarisation is often criticised for promoting divisiveness, scholars interested in sustainability narratives should be attentive to how polarisation can be used to critically interrogate taken-for-granted practices and sedimented social allegiances that inhibit the transition to a more sustainable society.

Polarisation is facilitated by a third feature of melodrama, a moral characterisation of public issues. Moral appeals in the melodramatic frame reinforce polarised socio-political conflict, often as characters take on the stock roles of victim, villain, or hero. Such appeals can potentially lead to a rupture in the established order to the extent that moral injustice "cannot be rectified though political compromises or minor adjustments to existing practices" [Schwarze, (2006), p.250]. With regard to sustainability, the moral dimension is especially critical to the extent that scientific and technical frames dominate public discourse and crowd out discussions of equity and social justice.

Finally, melodrama's polarised moral framing of issues also features strong emotional appeals. The 'monopathy', or singleness of feeling, created by melodrama pushes audience members to take sides; it encourages audience opposition to villains and alignment with victims and heroes. Sympathy, indignation, admiration, and other affective responses guide audience judgment in conjunction with the rest of the polarised moral framing of conflict. In fact, there is a long history of documentary and narrative filmmaking in and about Appalachian underground mining and MTR that promotes monopathy, including the documentaries Harlan County, USA (1976), Mountain Mourning (2006), and Leveling Appalachia (2009), and the narrative films Coal Miner's Daughter (1980) and Matewan (1987). In addition, such emotional appeals can encourage identification across spatial, temporal, and even species boundaries, which can lead to new premises for judgment as well as new possibilities for political coalition.

Considering how traditional US environmental organisations such as NRDC have relied on the melodramatic frame [Bsumek in Kinsella et al., (2008), p.81], its deployment in TLM is not surprising. For MTR in particular, the social and political 
struggles around coal extraction fit easily into the template of polarised moral conflict, which is perhaps why it has been the subject of so many films (Fesenmaier, 2008), novels (e.g., House, 2002) and even television shows (e.g., the FX series Justified). Scholars and journalists such as Burns (2007), Goodell (2007) and Scott (2010) have identified the significant tensions that exist in battles over MTR. They point to the immense environmental damage it creates; its long-term social and economic impacts on the Appalachian region; and the imbalanced power relations between politically vulnerable coal miners and unions on the one hand and the companies and local, state, and federal government policies that support them on the other. The melodramatic frame allows advocates to construct a coherent narrative that articulates the relationships between resource extraction, ecological degradation, human health, and social injustice.

\section{The Last Mountain and Appalachian melodrama}

In $T L M$, the melodrama depicts the struggles of communities located near Coal River Mountain in the Appalachian mountains of West Virginia and establishes their susceptibility to the risks posed by MTR. The mountains are introduced to the audience through aerial images of pastoral betrayal (Buell, 1998). The lush green fabric of the forested mountains appears ripped as the dull, grey scars of MTR come into the frame. Images of pristine winding rivers, mountainous vistas, and the sunlit greens and golds of foliage are juxtaposed with the repeated images of the mountains being blasted, scraped with giant draglines, and dumped into the surrounding rivers and hollows. As depicted in the film, the mountains and hollows of the region play two important roles in the melodrama: they provide the setting for the drama, and they serve as one of the primary victims of MTR. Similarly, in $T L M$, human victimhood is established by proximity to the MTR mines and operations: a ravine created by the unnatural floods coming off the denuded mountains cuts through local activist Maria Gunnoe's front yard; a massive boulder shot from one of the dynamite blasts sits a hundred yards from Bo Webb's garden; a coal processing plant towers directly over Ed Wiley's granddaughter's elementary school; and Jennifer Hall Massey shows the black mining particulates that pollute her tap water. In terms of environmental melodrama and MTR, victims are those people directly affected - physically, economically, and/or emotionally - by mining.

The cinematography of TLM invites audience identification with these victims, who are poignantly depicted in extreme close-up with the tops of their heads and bottoms of their faces outside the frame. The proximity evokes intimate connection. Audience members are allowed to peer into Maria Gunnoe's face as she talks about her family being saved by God during the flood, or Ed Wiley's as he explains his fear for his granddaughter's health. These images are shot head-on rather than from a side angle, making it appear momentarily that the audience and characters are part of the same world (Kress and Van Leeuwen, 2006). We too are sitting on Gunnoe's front steps as she tells her story. Although the audience can look deeply in her eyes, Gunnoe is not looking back. She and the other players are 'offered' for the audience's observation, evaluation and contemplation (Kress and Van Leeuwen, 2006).

In the melodramatic frame, just as there are victims, so must there be villains. In the first two-thirds of the film, the villains in TLM are, for the most part, mining executives and politicians. By way of victim testimony, voice-over narrative, and expert witnesses, energy company executives and politicians are depicted as profiteers and liars, who are 
cold-hearted to the plight of the victims and use manipulation, backroom deals, and influence peddling to achieve their goals of self-enrichment. NRDC senior attorney Robert F. Kennedy, Jr. (whose role is analysed in greater detail below) refers to the money moving from the coal industry into the campaigns of West Virginia politicians as 'legalised bribery'. In an example of duplicity, industry spokesperson Bill Raney points to a 1953 coal-fired power plant, espousing its 'clean' emissions and 'modern' technology. In a particularly telling storyline, then-governor Joe Manchin, a self identified 'friend of coal', is shown repeatedly deflecting requests from concerned parents and children to move an elementary school located next to a dust producing, coal loading silo and directly beneath an impoundment pond holding 2.8 billion pounds of coal sludge. As Ed Wiley explains, the school had lost four teachers and one student to what community members believed to be coal-related cancers. Upon return to the governor's office, officers forcibly remove several non-violent protestors - including a flag-wrapped, 91 year old woman in a wheelchair who grasps towards the arresting officer's arm for support as she is wheeled backward out of the office.

In keeping with the melodramatic form's emphasis on socio-political conflict, the primary villains in TLM are former President George W. Bush and Don Blankenship, former CEO of Massey Energy. The Bush Administration's modification of the Clean Water Act in 2002 to exclude regulation of MTR's valley fill is presented as the tipping point wherein environmental activists lost their legal foothold and MTR was allowed to proceed in Appalachia [see also Loeb, (2007), pp.268-269]. As the key executive at Massey Energy, Blankenship is characterised as single-handedly breaking the mining unions in West Virginia, damning the miners to longer hours, less pay and more dangerous working conditions. Under Blankenship's leadership, residents', children's and miners' lives are portrayed as being insignificant compared to maintaining the company's jaw-dropping profits. In 2009, the Upper Big Branch Mine, one of Massey's sites, accrued 500 health and safety violations, resulting in a $\$ 168,000$ fine - less than one hour's worth of profit. After explaining that the purposeful lack of compliance led directly to the loss of 29 miners' lives in a 2010 methane explosion, the screen goes black for a moment, allowing the villainy of Blankenship and Massey to sink in.

The hero is the most complicated of all the melodramatic roles in TLM, and the film's choice of Kennedy as hero reflects one of the documentary's central tensions: the tension between the local and the national, a focal point of this analysis that we explore in the following section. The typical hero in Appalachian culture appeals to rugged individualism, small town values, and hard work. That hero may also appeal especially to long-time residents of West Virginia, where gender roles are uniquely constructed and constrained (Scott, 2010). TLM recasts the hero in a different light, however, in the figure of Kennedy. His national influence and political pedigree are downplayed, but his obvious wealth puts him in sharp contrast to the local community who are marked as socioeconomic 'other' by their southern accents, clothing, and modest residences (Scott, 2010). This characterisation of the hero also deviates from the long-time, home-grown activists featured in other MTR-critical artefacts (e.g., Coal Country, 2009; House and Howard, 2009).

In a climactic moment of the film, Kennedy takes his case "directly to the coal industry" in a showdown with previously established villain Bill Raney. Sitting at a table in a Charleston, West Virginia cafe, Kennedy towers over a diminutive, slumped Raney. As Raney attempts to frame the argument as one of providing good jobs for professional miners, Kennedy counters with Massey's 60,000 health and safety violations, the 
'moonscapes' left from supposedly 'reclaimed' mine sites, and the poverty of the region. In the last statement of the scene, Raney describes the miners as 'practicing environmentalists', to which the filmmakers respond by cutting to a clip of an exploding mountainside. Both visually and verbally, Kennedy is seen as vanquishing the outspoken Raney.

Kennedy's heroism is bolstered through the commentary of others. Joe Lovett, a lawyer for the Appalachian Centre for Economy and the Environment, comments, "[Kennedy's] taken on this issue in West Virginia that he doesn't have to be here for. Nobody expected Bobby Kennedy to come, and he keeps coming back on his own, not for himself, I think, but really because he believes in helping this region". Local activists also are depicted fighting for the end of MTR, against the pollution of their communities and to save Coal Mountain, but the discourse surrounding these acts depicts the activists as reliant upon outside help. Unlike their representation in other films such as Burning the Future (2010), these activists are depicted as individuals or in small groups awaiting Kennedy, and are primarily the victims of MTR rather than its heroes. For example, Bo Webb, a local activist, argues, "It takes people outside the coal fields to come in and stop this insanity, because the only job ever has been a coal job and you do what the coal man says or you don't have a job. So outsiders have to come stop this". Kennedy, referring to the young environmental activists who have travelled to Appalachia to battle MTR, states, "These people who come from all over the country to save the Appalachian mountains; to me, they are heroes of American Democracy".

Kennedy's comment symbolises the persistent tension in the film between the local level and the national and global levels, a tension that distinguishes TLM from other films about MTR. In particular, the film attempts to move beyond the local melodrama of MTR to build a national case against coal-generated electricity. We refer to this as a 'scaling up' of the MTR melodrama. In the last third of the film, TLM scales up to implicate the viewer as a consumer of coal-fired electric power, to implicate coal companies and utilities as contributing to the global climate change crisis, and to encourage a particular kind of technological solution to these problems, namely wind power. In the next section, we analyse how this scaling up may weaken the melodramatic identifications otherwise fostered in the film.

\section{Scaling up: From MTR to global climate change}

It is not possible to neatly untangle the local melodrama in TLM from its national and global arguments. The filmmakers use images, statistics, interviews, and voiceovers throughout TLM to expand the circle of those who are at risk from MTR in West Virginia to those who are at risk from threatened water supplies, compromised air quality, and climate change nationwide. For example, the first image of the film is an aerial view of the Appalachian Mountains as a power plant comes into view on the horizon. The second image is of a brightly lit earth, depicted as covered in millions of tiny lights. The shot zooms in, through a stylised, brightly coloured apartment complex, and ends on a single burning light bulb. The text reads: "Almost 1/2 the electricity in the USA comes from burning coal. $16 \mathrm{lbs}$ of coal are burned each day for every man, woman, and child in the USA $1 / 3$ of that coal comes from the mountains of Appalachia". Although the national/global reach of coal is established in this opening sequence, the discussion of coal's broader consequences does not begin in earnest until over half way through the 
film. Our focus in this section, therefore, will be primarily on those segments in the film's second half in which the scaling up arguments are made most clearly.

At the hour mark, the film expands from the local melodrama set in Appalachia to facts and statistics addressing coal consumption and pollution in the rest of the USA. The change in narrative is marked by text that reads: "Mining and burning coal is the number 1 source of greenhouse gases worldwide". Alan Hershkowitz, a Senior Scientist for Natural Resource Defense Council, provides expert commentary, stating, "The coal industry imposes billions of dollars of health effects on citizens in literally every single state in this country". At this point, the film undergoes changes in the melodramatic roles already established; it includes greater numbers and different types of victims, villains, and heroes. In doing so, these characters become more diffuse, as does our identification with or against them.

For example, the localised villainy of Blankenship and Massey Energy continues in the film's second half with reference to their moral and legal evasions even in the face of mounting evidence of wrongdoing. Their villainy, however, is also supplemented with the figure of a new villain: the ominous and ubiquitous coal-fired power plant. Coal trains are shown travelling across the country. Six hundred red dots, representing the location of the plants, appear as a viral plague on a US map. Static photographs of pollutant-spewing industries are edited together with increasing speed, with none providing the context necessary to locate it in a region or community. The text reads, "Each year emissions from coal fired power plants contribute to more than 10 million asthma attacks, brain damage in up to 600,000 newborn children and more than 43,000 premature deaths". The responsibility for the plants' toxicity is explained in part by the active villainy of the Bush administration and, to some extent, the passive villainy of Obama's.

Similarly, victimhood is no longer contained within southern West Virginia. While most viewers of TLM will not travel to Appalachia or stay long enough to feel the health effects of living there, the film makes clear that the risks associated with coal will reach them eventually, whether by way of climate change or air and water pollution. As the location of the film enlarges from Coal Mountain to the nation, the circle of victimhood expands in equal measure. As with the Coal River melodrama, the filmmakers choose individual victims to represent the deleterious effects of coal on the collective. Ron Burris sits on his back porch in Shippingport, Pennsylvania, facing his house. Clearly visible over his shoulder is the Bruce Mansfield coal-fired power plant. Burris explains that his car must be repainted every couple years because the emissions from the plant eat down to the metal. Taking responsibility for the problem, the power plant has paid for each paint job. More difficult to prove and rectify are the recurring health problems that Burris attributes to his home's proximity to Bruce Mansfield. At the conclusion of his segment, the narrator states that Burris died of cancer shortly after his interview. Susan Bird, also a resident of Shippingport, attributes her son's autism to living near the power plant. As with Gunnoe, her face is closely framed as she questions whether her son would have been healthy had she chosen to live elsewhere.

The primary confusion in identification created by scaling up the melodrama involves the figure of the hero. In the local melodrama, Kennedy is the hero, albeit a problematic one given his positioning as an outsider. As the narrative expands out to a more global message about sustainable energy, however, the hero figure becomes as diffuse as the villain. On one hand, the viewer is implicated in the overall problem of coal burning and pollution. Every time we use electricity, the film implies, we are contributing to the injustices of MTR. On the other hand, the film suggests that we can become the hero in 
this larger story, both by consuming less power and also by supporting electricity generation from sources other than coal, particularly wind.

A flurry of images marks these shifts in identification. The audience is taken back to the beginning of the film with the neon-lit building and the single light bulb. Highly stylised, colour-saturated photographs of common sites of electricity use flash across the screen: an electrical outlet, a grocery store, a computer lab, an electric stove, school halls, streets, trains, and so on. The images represent the human-built environment, yet in nearly every photograph the settings are unoccupied - empty labs, empty halls, empty stores. The few inhabited images show only hands on a keyboard or blurred shadows of people boarding a train. In a direct and somewhat startling contrast from the deeply human, closely-shot faces that set the tone for the film, the conclusion asks the audience not to identify or empathise; instead, we are asked to locate ourselves as electricity users - the reason for the mining and burning of coal. The images then come with increasing speed until they spin themselves into a wind turbine, creating the path to redemption.

The film's solution to the problems of MTR, the devastating health effects of coal, and the hegemonic control of the energy companies is wind energy. The ridge of Coal River Mountain is presented as an excellent place for turbines, which would preclude the need to blow up and shave down the mountain. In discussing wind energy, Bo Webb states, "Coal River Mountain stands as a symbol of what could be, and what the future of America, not just of Appalachia, but what the future of America can hold". Single turbines are explained first by a small business owner and then a community mayor, each of whom has made the decision to switch from coal to wind power. Kennedy then explains the need for a new, nation-wide electricity transmission system. Importantly, this discussion of wind energy is framed as a local and individual response, rather than a political or systemic one. The socio-political conflict and emotional identifications established by the environmental melodrama fizzle at the foot of the windmill.

\section{Implications}

Our analysis of $T L M$ points to several potential pitfalls of breaking with melodramatic form in narratives about sustainability. As TLM scales up from its depiction of local struggles against MTR to a critique of national energy production and consumption, the film undercuts the rhetorical power of the melodrama in three ways. First, it erodes the strong identification that had been created between the viewer and the victims of MTR, perhaps as a result of moving away from the powerful local voices and storytelling traditions that have shaped the movement against MTR for years (House and Howard, 2009; Shapiro, 2010). Second, this breakdown in identification enables a shift away from collective action and political activism to individual responsibility, a move that promotes a limited type of action and which may constrain agency (Jensen et al, 2011; Morton, 2007). Third, the film fails to capitalise on the melodramatic depiction of the structures of power that sustain MTR and a coal-dominated electricity system. Instead, it endorses one particular technical solution, the wind turbine, and sidesteps the thorny politics of energy transition.

These criticisms of the film's narrative should not be read as opposition to wind power; indeed, we offer this analysis to explore how the melodramatic narrative might have been sustained in order to more effectively engage the challenges of energy 
transition. As such, we discuss these implications in terms of practical suggestions for sustainability advocates.

\subsection{Preserve moral and emotional identification}

The power of the MTR story lies in its local, contextualised roots; when the narrative is scaled up from this context to the depersonalised national context, the identifications created by the melodrama in TLM are confused. This is one of the principal challenges facing filmmakers wishing to tell stories about sustainability: the power of environmental melodrama lies in its ability to create identification between audiences and characters in the narrative based on moral and emotional appeals, yet these kinds of appeals are all too often missing from national discourses about energy policy. As a result, national narratives about energy may lack the texture of such humanised, local storytelling. For example, shifting the villain role from Don Blankenship to the figure of coal-fired power plants disrupts the complex affiliation between viewers and victims, and it complicates the polarisation that had been established around MTR in West Virginia earlier in the film.

Instead of turning the moral and emotional power of the melodrama against its villains, the film positions viewers primarily as electricity consumers. This falsely suggests that most consumers have the choice to determine where their electricity comes from and the ability to support or build windmills themselves to supply their electricity. In addition to exemplifying what Timothy Morton calls the "beautiful soul syndrome" in which our dirty electricity consumption habits end up purified at the point of consumption (Morton, 2007), this positioning of the audience elides the incredibly complex patterns and systems of energy production, distribution, and consumption currently in place. As a result, the ambiguous role offered to the audience is not only emptied of its moral and emotional resonance, but also provides extremely limited means of addressing the scale of problems associated with dependence on coal.

The narrative also struggles to promote moral and emotional identification as it scales up to the problem of climate change. Scholars have noted that this is one of the primary difficulties in communicating about climate change - the perpetrators of climate change, as well as its effects and therefore 'victims', are diffuse in time and space (e.g., Moser and Dilling, 2007). Terence Check (Kinsella et al., 2008) and DeLaure (2011) have argued that these same characteristics prevent environmental melodrama from effectively addressing the problem of climate change. According to Check "environmental advocates have struggled to frame climate change in melodramatic terms" because "there is no clear villain" and "the causes of climate change are diverse and systemic" [Kinsella et al., (2008), p.95]. Building on this assessment, DeLaure (2011, p.460) concludes "because melodrama locates blame with an evil other, it precludes audiences from understanding themselves as agents responsible for both problem and solution".

However, we contend that national-level melodramas could still be effective in creating moral and emotional identification. TLM moves in this direction in the middle of the film when it shows viewers how they are all victims of interlocking political and energy systems, but then it offers no strategies for challenging or dismantling those systems in the conclusion. If the film would have sustained the melodramatic emphasis on socio-political conflict and shared victimisation, it could have offered a more satisfying and coherent set of possible actions for viewers. 


\subsection{Turn individual responsibility toward collective action}

Preserving identification throughout a melodramatic narrative is also necessary to avoid conclusions that dwell on individual responsibility and 'small steps' approaches to sustainability (Crompton, 2008). Recall that melodrama has the potential to translate private troubles into public problems and display the interests and power dynamics at work in a particular situation. If this framing of shared public interests is lost, then it becomes easier for narratives to turn away from collective, political action and address viewers as isolated individuals.

$T L M$ concludes with cursory treatments of three ways that viewers might transform themselves from victims into heroes. First, the film presents model citizens and communities who are taking matters into their own hands by installing wind power. Second, it offers a vision of a future without coal-fired power plants. The last scene of the film depicts a power plant demolition, with the narrator simply stating, "The government of Ontario, Canada, has decided to decommission all of its coal fired power plants by 2014. It will replace them largely with renewable energy". The film discloses nothing about the context of Ontario's decision, such as whether ordinary citizens took heroic action to pressure the government to thwart the villainous coal industry. Third, the final frame of the movie gives the audience the following statement and a website address: "To get involved go to: http://www.thelastmountainmovie.com".

While no film can provide an exhaustive blueprint for action, these options offer limited resources for helping viewers connect their individual responsibility to collective action. On one hand, the film implores viewers to recognise that they are part of the problem of MTR, primarily through their energy consumption. This suggests that individual responses can address the problems of energy use and climate change. On the other hand, it also suggests that groups of committed citizens can band together behind renewable energy (in the form of wind turbines) and therefore shift energy practices away from coal. Certainly, this is one of many solution spaces that may address both energy production and carbon emissions. Yet there is little discussion of the political, economic, and policy landscapes in which such decisions must be made. Decisions to erect wind turbines appear to occur in a politically neutral space, in contrast to the highly charged and seemingly corrupt atmosphere surrounding MTR. Furthermore, the film implies that wind power is a universally feasible solution to our energy and climate problems, which obscures the 'wickedness' of both (Conklin, 2005). Glossing over the relationship between individual responsibility and collective action leaves the call to build more wind turbines ringing somewhat hollow.

The emphasis on individual responsibility in $T L M$ reinforces the heroic consumer position described in the previous section. In doing so, the film fuels "the erosion of confidence in political institutions and citizen capacities to effect change" [Maniates (2002), p.57]. As Michael Maniates (2002, p.57) has argued, such erosion of confidence diverts citizen action to "the one arena of their lives where they command the most power and feel the most competent-the sphere of consumption". TLM exemplifies this diversion; even though the melodramatic narrative of the film offers a compelling story about the villainous collusion between industry and government, it stops short of guiding viewers to resist that collusion, other than through vaguely supporting wind power or turning the lights off more frequently. Because of this break in the melodramatic narrative, the film misses an opportunity to turn individual responsibility toward collective political action. 


\subsection{Go beyond the technological fix}

The political conflicts and moral harms articulated by environmental melodrama imply that solutions must be more comprehensive than merely increasing efficiency or implementing new technologies. Yet that is precisely what is on offer at the end of TLM. To its credit, the film suggests putting windmills on Coal River Mountain can address multiple dimensions of sustainability: it can save the mountain, provide longer-lasting and higher-quality jobs, and produce clean electricity. We do not dispute that Coal River Mountain could be a successful site for windmills and enhance the environmental, social, and economic well-being of southern West Virginia. Here again, however, scaling up the MTR argument to larger arguments about energy and climate change proves somewhat problematic, and the choice to put forth windmills as panacea - in West Virginia and nationally - raises more questions than it answers.

On a local level, if wind power is an excellent choice for Coal River Mountain, what barriers are in the way of building the windmills: financing, land ownership, political leadership, or coal industry stonewalling? Nationally, if we get nearly half of our electricity nationwide from burning coal, how many windmills will we need to build to replace that capacity? Why have not we done this so far? The Rhode Island school in $T L M$ that adopts wind power is both an inspirational story and a puzzling one within the context of the film. The school's story proves that wind can be a viable source of electricity production, but the school operates in a seemingly frictionless environment, compared to the deeply politicised and conflict-ridden setting of southern West Virginia. It implies that simply adopting this technology will resolve the complex problems depicted in the first two-thirds of the film. Although it may function as a political shorthand for support of renewable energy in general, it does not do justice to the (political) complexity of our current energy and climate crises.

The film's uncritical support of wind as a technological solution also detracts from melodrama's formal capacity to mobilise audiences against the villain - in this case, the Blankenships, Bushes, and Masseys. By focusing on an impersonal, if noble, technical solution, the villains are made irrelevant rather than vanquished. This saps the energy of a melodrama by removing its primary motive force - ridding the world of villainy and saving the victims. In other words, the emphasis on wind turbines sidesteps a fight with the villain, shifting a polarised political issue toward a technological solution and away from political conflict.

\section{Conclusions}

$T L M$ is, in many ways, a compelling sustainability tale; regardless of one's feelings about American reliance on coal or one's perspective on climate change and its causes, audience identification with the sick, displaced, and despairing in small town southern West Virginia is powerful. Viewers are invited into the filmmakers' polarised, melodramatic framing of the MTR conflict and encouraged to perceive a fundamental imbalance of power, rights, goods, and ills in West Virginia. There is too much power in the hands of corporations and not enough in the hands of the people, the state and local government does not seem to be doing enough to check or regulate this power and the environmental commons are being irreparably destroyed. 
Yet the melodramatic frame established during the first hour of the film is disrupted as the MTR problem is scaled up to address national energy and climate crises. As we have shown, the last third of the film breaks with melodramatic form, displacing the political possibilities implicit in the first part of the film and offering individualistic and depoliticised avenues for change. If TLM had carried through with the melodramatic frame, a different sustainability narrative might have emerged.

Building on the implications discussed above, the film could have sustained a melodramatic framing by emphasising how we are all the victims of coal companies and their cronies. It might have elaborated on the ways that the coal industry and their partners exercise control over the political economy of power generation, delivery and use, leaving those of us who use energy at their mercy. Like the series of vignettes about coal's effects on human health, the film could have assembled parallel stories of citizens in other regions being thwarted by corporate power and political corruption in the attempt to get utility providers to offer renewable energy. Conversely, dramatic stories of citizens winning legislative victories or concessions from utility providers could have modelled effective political agency. This framing would position audiences as already desiring alternative energy sources, and provide them with a call to action and means to address the complex patterns and systems of energy production, distribution and consumption. This framing also would unambiguously situate and constitute the audience within the narrative as already opposed to the coal-industrial system and as agents who are called upon to act in concert with the activists fighting coal companies and political corruption in Appalachia.

Our analysis and 'alternative ending' for $T L M$ enhances theorisation of environmental melodrama by revealing how the turn toward solutions presents a potential rupture point for melodramatic narratives. To prevent this rupture, advocates not only need to show how victims transformed themselves into heroes; they must show how audiences, too, can become heroes, and not only through revised consumption practices. Moreover, this heroism must be contextualised by other melodramatic elements in order to retain possibilities for political agency. Monopathic identification with victims is not enough; nor are depoliticised responses that ignore the roots of systemic problems. Further research should examine how melodramatic narratives negotiate the movement from problem to solution, and how audiences are positioned in the process.

Finally, this alternative ending suggests that perhaps the most fundamental challenge faced by those who wish to use environmental melodrama to advance sustainability is how that frame can be put in the service of a more generalised political platform. We have suggested one way in which environmental melodrama might be utilised to scale up a localised issue like MTR to the national or global level. Our larger point is that those who construct sustainability narratives must pay attention not only to the content of their narratives, but also to how narrative form enables and constrains different forms of agency and action.

\section{References}

Buell, L. (1998) 'Toxic discourse', Critical Inquiry, Vol. 24, No. 3, pp.639-665.

Burns, S.S. (2007) Bringing Down the Mountains: The Impact of Mountaintop Removal on Southern West Virginia Communities, West Virginia University Press, Morgantown, WV. 
Charland, M. (1990) 'Rehabilitating rhetoric: confronting blindspots in discourse and social theory', Communication, Vol. 11, pp.253-264, in Lucaites, J., Condit, C. and Caudill, S. (Eds.) (1999) Contemporary Rhetorical Theory: A reader, The Guilford Press, New York.

Conklin, J. (2005) Dialogue Mapping: Building Shared Understanding of Wicked Problems, Wiley, Hoboken, NJ.

Cox, R. (2010) Environmental Communication and the Public Sphere, Sage Publications, Thousand Oaks, CA.

Crompton, T (2008) Weathercocks and Signposts: The Environment Movement at a Crossroads, World Wildlife Federation-UK, Godalming, UK.

DeLaure, M. (2011) 'Environmental comedy: no impact man and the performance of green identity', Environmental Communication: A Journal of Nature and Culture, Vol. 5, No. 4, pp.447-466.

Fesenmaier, S. (2008) Films on Stripmining and Mountaintop Removal Mining, Ohio Valley Environmental Coalition [online] $\mathrm{http} / / / w w w . o h v e c . o r g /$ links/mountaintop_removal/mtr_films.pdf (accessed 14 February 2012).

Goodell, J. (2007) Big Coal: The Dirty Secret behind America's Energy Future, Houghton Mifflin Harcourt, New York.

House, S. (2002) Clay's Quilt, Ballantine Books, New York.

House, S. and Howard, J. (2009) Something's Rising: Appalachians Fighting Mountaintop Removal, University Press of Kentucky, Lexington, KY.

Ivakhiv, A. (2008) 'Green film criticism and its future', Interdisciplinary Studies in Literature and Environment, Vol. 15, No. 2, pp.1-28.

Jensen, D., McBay, A. and Keith, L. (2011) Deep Green Resistance: Strategy to Save the Planet, Seven Stories Press, New York.

Kinsella, W.J., Bsumek, P.K., Walker, G.B., Check, T., Peterson, T.R. and Schwarze, S. (2008) 'Narratives, rhetorical genres, and environmental conflict: responses to Schwarze's 'Environmental melodrama', Environmental Communication: A Journal of Nature and Culture, Vol. 2, No. 1, pp.78-109.

Kress, G.R. and Van Leeuwen, T. (2006) Reading Images: The Grammar of Visual Design, 2nd ed., Routledge, New York.

Loeb, P. (2007) Moving Mountains: How One Woman and her Community Won Justice from Big Coal, University of Kentucky Press, Lexington, KY.

Maniates, M. (2002) 'Individualization: plant a tree, buy a bike, save the world?', in Princen, T., Maniates, M. and Conca, K. (Eds.): Confronting Consumption, MIT Press, Cambridge, MA.

Morton, T. (2007) Ecology Without Nature: Rethinking Environmental Aesthetics, Harvard University Press, Cambridge, MA.

Moser, S.C. and Dilling, L. (Eds.) (2007) Creating a Climate for Change: Communicating Climate Change and Facilitating Social Change, Cambridge University Press, Cambridge, UK.

Press, The Last Mountain Movie [online] http://thelastmountainmovie.com/press/ (accessed 14 February 2012).

Rosteck, T. and Frentz, T.S. (2009) 'Myth and multiple readings in environmental rhetoric: the case of an inconvenient truth', Quarterly Journal of Speech, Vol. 95, No. 1, pp.1-19.

Schneider, J. and Miller, G. (2011) 'The impact of no impact man: alternative hedonism as environmental appeal', Environmental Communication: A Journal of Nature and Culture, Vol. 5, No. 4, pp.467-484.

Schutten, J.K. (2008) 'Chewing on the grizzly man: getting to the meat of the matter', Environmental Communication: A Journal of Nature and Culture, Vol. 2, No. 2, pp.193-211.

Schwarze, S. (2006) 'Environmental melodrama', Quarterly Journal of Speech, Vol. 92, No. 3, pp.239-261. 
Scott, R. (2010) Removing Mountains: Extracting Nature and Identity in the Appalachian Coalfields, University of Minnesota Press, Minneapolis, MN.

Shapiro, T. (2010) Mountain Justice: Homegrown Resistance to Mountaintop Removal, for The Future of Us All, AK Press, Oakland, CA.

Take Action, The Last Mountain Movie [online] http://thelastmountainmovie.com/take-action/ (accessed 14 February 2012).

Wolfe, D. (2009) 'The video rhizome: taking technology seriously in The Meatrix', Environmental Communication: A Journal of Nature and Culture, Vol. 3, No. 3, pp.317-334. 